\title{
Improving Students Engagement through Social Media: A Case Study of a Private University in Malaysia Using Facebook
}

\author{
Tze Ying Sim ${ }^{1}$, Dewika Naidu ${ }^{1 *}$, Devandran Apparasamy ${ }^{1}$ \\ ${ }^{1}$ Sunway University, Malaysia, no. 5, Jalan University, Bandar Sunway, 47500 Malaysia. \\ * Corresponding author. Tel.: +012 603 8655; email: dewikan@sunway.edu.my \\ Manuscript submitted November 10, 2014; accepted December 28, 2014.
}

\begin{abstract}
This research looks into implementation of Facebook in six different courses covering Science, Engineering and Technology subjects. The initial purpose of using Facebook in the class is to communicate with the students more effectively, as communication through the formal channel (through learn management system) had not been successful. It is expected that by sending two to three notices per week to the students as a gentle reminder for reading material, assignments or even tests, students would be more motivated to engage in the course content. The research results showed that students are positive in using Facebook as an engagement tool. The engagement also encourages their participation in class, and enhances their interest towards the subject content. Features that influenced this engagement are also looked into.
\end{abstract}

Keywords: Engineering education, social network services, Facebook, Web 2.0, learning technology.

\section{Introduction}

There is no definite definition of mobile learning. Learning on the move can be the generalization of this term, some calls it "handheld learning" [1], focusing on devices that are small and portable, for example, handheld computers and smart phones. The students have these devices with them most of the time and would be able to use the devices for learning whenever and wherever they wish to. Mobile Learning in its simplest form is sending short messages service (SMS) or text messages via hand phones to the students [2]-[6]. With the development of smart phones and tablets, comes along a list of third party application that can be used for mobile learning [7]-[9]. Apart from that there is a whole list of Web2.0 applications that are available for both educators and students [10], [11]. Elias drew eight "User Interface Design" guidelines for mobile learning, they include equitable use, flexible use, simple and intuitive, perceptible information, tolerance for error, low physical and technical effort, community of learners and support, and instructional climate [12]. This paper looks into using mobile technology as a way to increase the communication with the students. It is expected that with active communication between lecturers and students, the students would be more engaged with the course content.

\section{Related Work}

There are various works done on using Facebook in a class [7]. Junco [13], discovered that Facebook usage, significantly negatively influence the student engagement in term of class preparation, but positively 
influence the time spent in co-curricular activities. The findings from [14] mentioned that students are generally reluctant to use Facebook as a learning tool, preferring to keep learning out of their private life. There is another study by Judele et al., indicating that grading and participation in Facebook has adverse effect on students' preparation time [15]. Jamil et al., mentioned that the usage of Facebook has no impact on academic grades and should be further investigated for the communication aspects [16]. Maleko et al. finds students are reluctant to use Facebook as a learning tool [17]. However, students participating in the Facebook discussion group are more active than the Blackboard discussion group [17].

This research would re-visit some of the aspects investigated above, especially the proposal from Jamil concerning the communication aspect of Facebook. Chen mentioned that interaction within Facebook did encourage a group of students to understand the course content and to work more often with the course content [18]. It is expected with better communication between the lecturer, and the students, the students' engagement within the course would improve.

\section{Methodology}

\subsection{Motivation}

In a private higher education institute, having students enrolled in the courses, and eventually passing the paper and retaining them in the program until they graduate is an important source of income. However, in retaining the students, the quality of the students' needs to be ensured. Students cannot be awarded a pass, in order to reduce the attrition rate. The research takes place in the department of "American Degree Program", where sixty percent of the final grade work consists of coursework. By submitting the coursework on time, and engaging in class activities, students would earn marks that contribute to the final grade work. Therefore, it is important for the students to attend the classes and be engaged in the class. Devadoss and Foltz found significant positive influence of class attendance on students' performance[19]. Among the skills related to class attendance are note taking, comprehension, and study habits. When a student is engage in the class content, they would work more on the content, be more prepared for the class, and be more interested in attending the class. A group of lecturers got together to identify the steps that can be taken to enhance the interest of students to engage with the course content. The area of focus is to enhance class engagement through lecturers' and students' communication.

The initial idea was to encourage students by sending one or two messages per week. The content of the message could be informing them of available resources that was uploaded in the learn management system, a reminder about an upcoming test or assignment deadline, an interesting article concerning the class, or just words of encouragement. Four out of thirteen chapters on "Mobile Learning: Malaysia Initiatives and Research Findings" was on the application of SMS and mentioned about the positive impact of SMS towards encouraging students [20].

\subsection{Applications Consideration}

As mentioned in the "Introduction Section", there are numerous ways to engage students. Among them are using various Web 2.0 technology. However, as this research focuses on improving students' engagement through lecturers' and students' communication, the applications considered are narrowed down to short message using mobile phone (SMS), Whatsapp (whatsapp.com), Twitter (twitter.com), and Facebook (facebook.com).

The initial consideration was to use SMS as proposed by other researchers. However, privacy is an issue. The lecturers would want to keep their mobile number private. Creating a "Whatsapp" group is also out of the question, as this requires the lecturer to have all the students' phone number, and the students would also need to have the lecturer's phone number. The third consideration was to have a Twitter account and 
request the students to follow the lecturers' tweets. This idea did not follow through as the lecturers are not familiar with Twitter. The final decision was to use Facebook. This is based on the observation that most students have a Facebook account, and at times can even be seen "Facebooking" in the class. Irwin et al.also found that Facebook improves communication between lecturers and students[21].

\subsection{Procedure}

The first step is to consider the account to be used to communicate with the students. One of the main concern among the lecturers is the privacy issue. The lecturers are concerned if their private life is exposed to the students. There are two options to solve this problem. The first option is to assign students' friend's request to a specific group. However, this would be tedious as the lecturer needs to accept the students' request and then assign them to a specific group. The private postings from the lecturers' would then be made unavailable to this group. This might be tedious as the lecturer would need to monitor the privacy setting of every posting. The second option is to create an official Facebook account dedicated specially for the students. This would clearly separate the private and working sphere of the lecturers. The lecturers in this research opted for the second option.

The second step is to consider the methods to connect to the students. The lecturers can add each students as friends. However, it is also important to categorize the students, as a lecturer would be teaching more than a course. Facebook offers the group option. The lecturers created "groups" according to the courses taught. The groups are created as an open group. Open group enables any member to add new member into the group. This would reduce the lecturers' administrative workload as students can add other students. During the first week of the lesson, students are informed about this Facebook group and they are requested to join the group. Eventually at week three, the specific Facebook group can be changed to a closed group. This is because the enrollment of the course is finalized, and furthermore, most of the students enrolled in the course have joined the group.

The third step is to ensure a minimum number of communication happens within the group. The lecturers are advised to post at least two to three posts a week. Information shared on the Facebook group would also be posted in the university learn management system (named eLearn). This is to cater for students who do not have a Facebook account. From the 103 students surveyed, only one student does not have a Facebook account.

The participation in Facebook is not graded. The students participated on voluntarily basis. The lecturers started posting at week two. The participating classes in this research are General Chemistry I (CHEM 1033), General Chemistry II (CHEM 1053), Introduction to Computer Applications (CSCI 1013), Programming 1 (CSCP 1014), Dynamics (ENGR 2023), and Thermodynamics (ENGR2033). The class size ranges from 5 to 40 students. Surveys are conducted to evaluate the impact of this implementation.

\section{Data Collection}

Data collected for this research are mainly from three sources - the survey for the student, the postings in the Facebook group, and the feedback from the lecturers.

\subsection{Students Survey}

A thorough survey for all the participating classes was conducted at week nine. The survey was divided into the following categories: demographic, impact of engagement, activities on Facebook group, features influencing the engagement on Facebook, and comparison between Facebook and eLearn. There are 103 feedbacks for this survey. The students' survey are discussed in Section 5 - Findings and Discussion on Student's Survey. 


\subsection{Postings in Facebook Group}

The postings in the group would inform us on the information that is being shared, the participation of the students, and the most active user in the group. Postings in each group are analyzed to identify the following information:

The most active users who starts a post (presumably the lecturer)

The number/percentage of students participating in the discussion

The type of content that was posted, whether it was course related or just for fun postings. As well as the number of postings of lecturer versus students in each category

Findings and discussion on postings' data are discussed in Section 6 - Findings and Discussion on Posting of Data.

\subsection{Lecturers' Feedback}

The participating lecturers are requested to write a short essay concerning their experience of using Facebook as a tool to engage students in the class. They are requested to write on the following aspects:

a) the experience of using Facebook to engage with students for the very first time

b) the ease of use

c) the difficulty that one faced

d) the content posted

e) the students' reply

f) the comparison of this engagement as compared to the previous semester

Findings and discussion on lecturers' feedback are discussed in Section 7 - Findings and Discussion on Lecturer's Feedback

\section{Findings and Discussion on Student's Survey}

The data obtained from the survey conducted would be analyzed in detail.

\subsection{Demograhic}

Table 1. Participants of Survey

\begin{tabular}{|l|l|l|l|}
\hline Courses & $\begin{array}{l}\text { Students Took } \\
\text { Part in Survey }\end{array}$ & $\begin{array}{l}\text { Total Number } \\
\text { of Students }\end{array}$ & $\begin{array}{l}\text { Percentage of } \\
\text { Participation }\end{array}$ \\
\hline CHEM 1033 & 39 & 40 & $98 \%$ \\
\hline CHEM 1053 & 18 & 24 & $75 \%$ \\
\hline CSCI 1013 & 26 & 30 & $87 \%$ \\
\hline CSCP 1014 & 13 & 19 & $68 \%$ \\
\hline ENGR 2023 & 2 & 2 & $100 \%$ \\
\hline ENGR 2033 & 5 & 8 & $63 \%$ \\
\hline Grand Total & 103 & 113 & \\
\hline
\end{tabular}

As shown in Table 1, 103 students participated in the survey. Averagely, about $82 \%$ of the students took part in this survey. This would be able to provide a general view on the impact of this implementation. Out of the 103 students, only 26 students are female as compared to 77 male students. Therefore, no analysis based on gender would be conducted. The class size covered in this survey are small and middle class sizes [22].

\subsection{Impact of Engagement}


The students asked if the implementation of Facebook in class:
a) helped them to participated in the class discussion
b) provided them a venue to raise question
c) made the class more interactive
d) encouraged them to work on the course content
e) enabled them to be engaged with the class while being out of the class
f) helped the students to share the lab data

The options are of Likert scale with 1 as "Strongly Agree" and 5 as "Strongly Disagree". Findings of the survey are as in Table 2. The items are labeled in alphabet as the list above.

Table 2. Impact of Engagement

\begin{tabular}{|c|c|c|c|c|c|c|}
\hline & $\mathrm{a}$ & $\mathrm{b}$ & $\mathrm{c}$ & $\mathrm{d}$ & $\mathrm{e}$ & $\mathrm{f}$ \\
\hline $\mathbf{N}$ & 102 & 102 & 102 & 102 & 102 & 97 \\
\hline Mean & 1.745 & 1.755 & 1.804 & 1.765 & 1.725 & 2.021 \\
\hline $\begin{array}{c}\text { Std. } \\
\text { Deviation }\end{array}$ & 0.7404 & 0.7504 & 0.7713 & 0.6919 & 0.6473 & 0.9463 \\
\hline Skewness & 1.494 & 1.298 & 1.147 & 1.081 & 0.557 & 0.937 \\
\hline
\end{tabular}

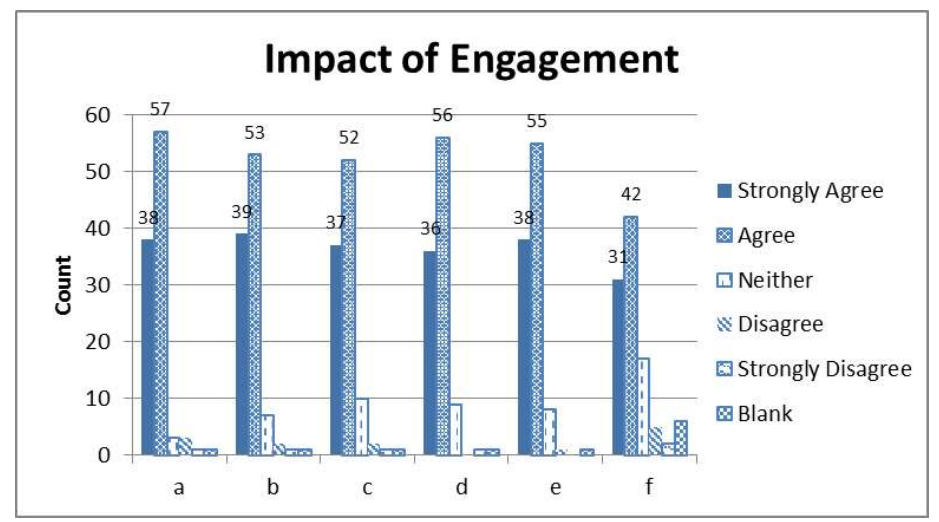

Fig. 1. Impact of engagement.

By observing the mean and skewness of graphsas in Fig. 1 and Table 2, it is observed that most data are on the left side of the graph. This indicates that most of the students' response are between strongly agree and agree for point a) to f). The less agreed point is f) where the mean is at 2.021 and it has a bigger standard deviation at 0.9463 . From the findings above this leads to the first conclusion:

Conclusion 1. The implementation of Facebook in class does encourage the participation and engagement of students in class.

\subsection{Activities on Facebook Group}

The next part of the survey looks at the activities of the students. Only activities concerning the group are asked. The three activities are starting a post, replying a post and liking a post (see Table 3). The students are supposed to answer the questions on a Likert scale of three, with 1 as most frequent, 2 as moderately frequent and 3 as less frequent.

According to the mode for the activities, the highest is to like a post, with 41 students replying with most frequent and 50 students with moderately frequent as shown in Fig. 2. This is because like is the simplest 
activity. However, liking a post might not mean much other than to acknowledge it. For example, the survey link was posted for survey 2 was posted in the group. For one of the course, 20 students seen the post, 17 students liked the post, but only 1 responded to the survey. The rest of the students only responded to the survey when this matter was highlighted in the class.

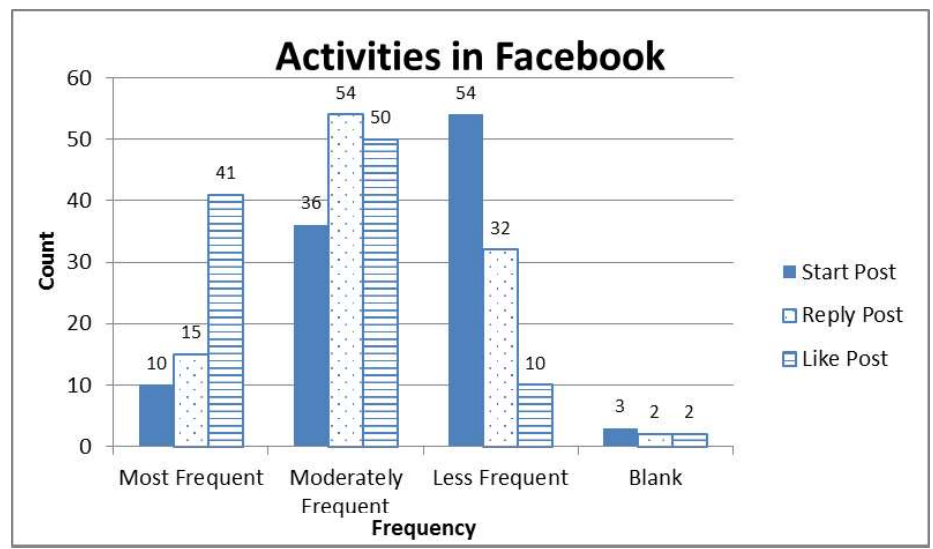

Fig. 2. Activities on Facebook group.

The second highest activity is reply post. Almost $70 \%$ of the students mentioned that they most frequent or moderately frequent reply to post. The least participated activity is starting a post. This indicate that the lecturer is the initiator for most of the postings. This hypothesis would be confirmed by analyzing the postings on Facebook in Section 6 - Findings and Discussion on Posting of Data.

Table 3. Activities in Facebook Analysis

\begin{tabular}{|c|c|c|c|c|}
\hline & & StartPost & ReplyPost & LikePost \\
\hline \multirow[t]{5}{*}{ StartPost } & Pearson Correlation & 1.000 & $0.574^{* *}$ & $0.224^{*}$ \\
\hline & Sig. (2-tailed) & & 0 & 0.025 \\
\hline & Sum of Squares and Cross-products & 44.64 & 25.08 & 9.64 \\
\hline & Covariance & 0.451 & 0.253 & 0.097 \\
\hline & $N$ & 100 & 100 & 100 \\
\hline \multirow[t]{5}{*}{ ReplyPost } & Pearson Correlation & $0.574^{* *}$ & 1.000 & $0.489^{* *}$ \\
\hline & Sig. (2-tailed) & 0 & & 0 \\
\hline & Sum of Squares and Cross-products & 25.08 & 44.14 & 20.58 \\
\hline & Covariance & 0.253 & 0.441 & 0.208 \\
\hline & $N$ & 100 & 101 & 100 \\
\hline \multirow[t]{5}{*}{ LikePost } & Pearson Correlation & $0.224^{*}$ & $0.489^{* *}$ & 1.000 \\
\hline & Sig. (2-tailed) & 0.025 & 0.000 & \\
\hline & Sum of Squares and Cross-products & 9.64 & 20.58 & 41.49 \\
\hline & Covariance & 0.097 & 0.208 & 0.415 \\
\hline & $N$ & 100 & 100 & 101 \\
\hline
\end{tabular}

When checking the correlation between the different activities, it is observed that students who replied posts have significant correlation in starting a post at and liking a post at the 0.01 level. However, the correlation significant between starting a post and liking a post is only valid at the 0.05 level. 


\subsection{Features Influencing the Engagement in Facebook}

The next section explores the technical and community features that influence the engagement. This would help learn management developer, and acquirer to make better decision when looking into the features for a particular system of interest.

Technical Features in Facebook: The first area involves the technical features in Facebook, the features evaluated are:
a) login cached do not have to login to access updates
b) automatic notifications when there are new updates
c) automatic updates even while using the application
d) the ease of posting comments, documents or photos
e) my "friends" can see my postings

The response are of Likert scale with 1 as "Strongly Influence", 2 as "Influence", 3 as "Neither", 4 as "No Influence", and 5 as "Not at all a Factor".

Table 4. Features Influencing Engagement

\begin{tabular}{|l|c|c|c|c|c|}
\hline & $\mathrm{a}$ & $\mathrm{b}$ & $\mathrm{c}$ & $\mathrm{d}$ & $\mathrm{e}$ \\
\hline $\mathbf{N}$ & 100 & 101 & 100 & 99 & 101 \\
\hline Mean & 2.25 & 1.71 & 1.81 & 1.78 & 2.08 \\
\hline Std. Deviation & 1.03 & 0.77 & 0.86 & 0.84 & 1.07 \\
\hline Skewness & 0.79 & 0.95 & 1.35 & 1.29 & 1.16 \\
\hline
\end{tabular}

Table 4 shows all the categories from a) to e) are positively skewed. This indicates that most of the students chose the answer Strong Influence, Influence and Neither. Observing the mean and standard deviation it can be concluded that factor "b) automatic notifications when there are new updates", "d) the ease of posting comments, documents or photos" and "c) automatic updates even while using the application" are the top three technical features, in ascending manner. The fourth most important factor is "e) my friends can see my postings" followed by "a) login cached - do not have to login to access updates."

From the findings above the second conclusion is drawn.

Conclusion 2. The "automatic notifications of updates" is the most important feature that positively influenced the students' engagement in Facebook.

The second highest factor is factor "the ease of posting comments, documents or photos". The content structure in Facebook is a "flat structure" as compared to eLearn, which has a "drill down" structure. For example as shown in Table 5, only 3 steps are required to post a message in Facebook, while it requires 6 steps in eLearn. Logging in to Facebook is not considered as a step in Facebook, as most students are logged in on their devices.

Table 5. Steps to Post a Message

\begin{tabular}{|c|c|}
\hline Facebook & eLearn \\
\hline & Login to eLearn \\
\hline Click on the group & Click on Discussion \\
\hline & Select the suitable forum \\
\hline & Select the suitable thread \\
\hline Write the post content & Write the content \\
\hline Post the message & Submit the content \\
\hline
\end{tabular}

The example above applies to when posting a video or a photo. Apart from that, Facebook does not offer 
the option to style the particular object, for example adding border, changing line width, etc. This might be an advantage as this keeps the user interface simpler. Apart from that, Facebook uses AJAX programming [23], this is more responsive than the basic HTML code used in eLearn. This leads to the third conclusion

Conclusion 3. The ease of posting comments, documents, or photos positively influenced the students' engagement in Facebook.

Even though the factor a, login cached scored the lowest among the five factors, $65 \%$ of the students agreed that this feature do influence the engagement using Facebook. The convenience of not having to key in the username and password every time you need to use the application has a positive factor. This leads to the fourth conclusion:

Conclusion 4. Cached login positively influence the students' engagement in Facebook.

Community Features in Facebook: The second feature to be discussed is the community feature in Facebook. Mainly, on one issue that concerns many - the privacy issue.

The students are requested to select the level of privacy that would best represent their interests. They are allowed to choose one or more from the following options:
a) Having my course mates as my "Friends"
b) Having my lecturer as my "Friends"
c) Joining a group for my course - with/without course mates being "Friends"
d) Other

The feedbacks from the students are as of Table 6.

Table 6. Privacy Level

\begin{tabular}{|c|c|c|}
\hline Legend & Description & Respondent \\
\hline $\mathbf{A}$ & Having my course mates as my "Friends" & 19 \\
\hline \multirow{2}{*}{ B } & Having my course mates as my "Friends", & \multirow{2}{*}{19} \\
\hline & Having my lecturer as my "Friends" & \\
\hline \multirow{3}{*}{ C } & Having my course mates as my "Friends", & \multirow{3}{*}{30} \\
\hline & Having my lecturer as my "Friends", & \\
\hline & $\begin{array}{l}\text { Joining a group for my course - with/without course } \\
\text { mates being "Friends" }\end{array}$ & \\
\hline \multirow[b]{2}{*}{ D } & Having my course mates as my "Friends", & \multirow[b]{2}{*}{3} \\
\hline & $\begin{array}{l}\text { Joining a group for my course - with/without course } \\
\text { mates being "Friends" }\end{array}$ & \\
\hline $\mathbf{E}$ & Having my lecturer as my "Friends" & 4 \\
\hline \multirow{3}{*}{$\mathbf{F}$} & Having my lecturer as my "Friends", & \multirow{3}{*}{3} \\
\hline & Joining a group for my course - with/without & \\
\hline & course mates being "Friends" & \\
\hline G & $\begin{array}{l}\text { Joining a group for my course - with/without course } \\
\text { mates being "Friends" }\end{array}$ & 23 \\
\hline \multirow[t]{2}{*}{$\mathbf{H}$} & (blank) & 2 \\
\hline & Total & 103 \\
\hline
\end{tabular}

As in Fig. 3, the highest grouping is selecting all the first three options, which are option a, b, and c, 30 students selected this combination. This is followed by only option c selected by 23 students. The next in the list are 20 students selecting option a, and option b. Followed by 19 students selecting option $a$, and $b$.

Generally, 72 students selected the option "having my course mates as my friends", and 57 students selected the option of "having lecturer as their friends". This is contradicting to the earlier belief from the eLearn experts that students would prefer to keep their private life private, and have another account for 
their study. Instead, the privacy barrier lies with the lecturer. All the three lecturers participating in this research as well as other peers, who are using Facebook for class, prefer to setup a "work account" to communicate with the students. This leads to the fifth conclusion:

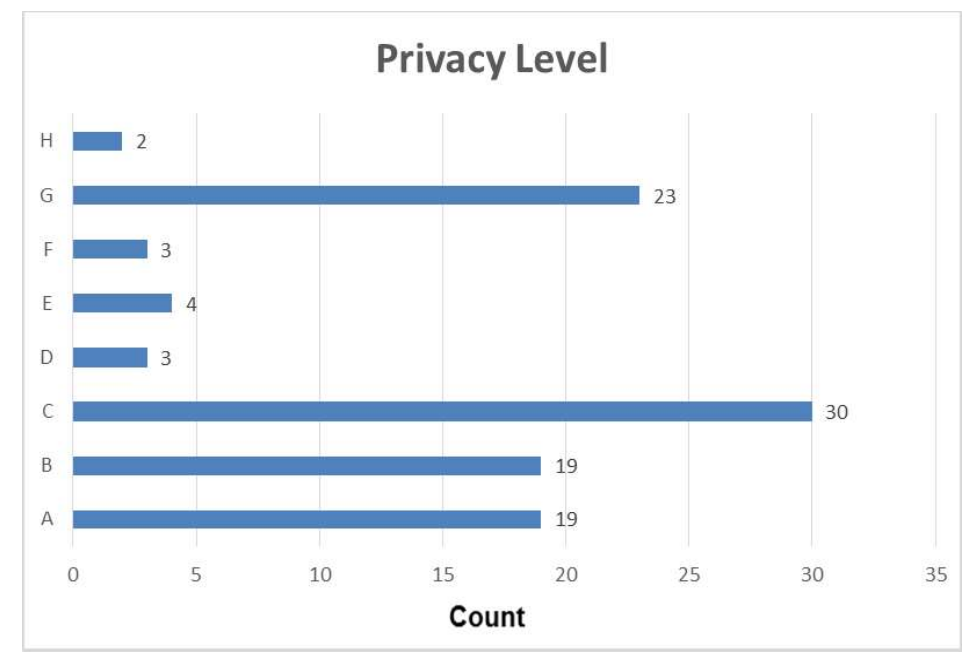

Fig. 3. Privacy level preferences by students.

\section{Conclusion 5. Students do not mind having course mates and lecturers as their "Friends".}

\subsection{Comparison of Facebook and eLearn}

The students were asked on the number of hours they spent each week, from Monday to Sunday, on eLearn and on Facebook. This is an open ended question. Students' answers that are quantifiable would be quantified. For example if it is written between 1 to 2 hours, 1.5 would be used. However if the answer is a few hours, then this would not be recorded. From the analyzed data, students spend averagely 1.68 hours a week on eLearn. The longest hour is 14 hours a week. The mode is at 1 hour with 37 students. On the other hand the average hours spent on Facebook per week is 13.73 hours, with the mode at 4 hours and 9 hours with 9 students. The longest hour spent is recorded by the remark "All the time" and "Countless" by 2 students each. This clearly shows that students spend a substantial amount of time on Facebook.

The students are also asked if "the same level of participation and discussion can take place in eLearn", if the features available on Facebook as discussed in section D, are also made available in eLearn. To this question, 83 students answered no, 17 students answered yes, 2 students answered maybe and 1 student did not answer. This clearly shows that a majority of the students do not believe that the same level of engagement would take outside Facebook. Both observations discussed, leads to the sixth conclusion.

Conclusion 6. Facebook is the right tool to encourage students' participation as that is the environment that they are comfortable with for discussion.

\section{Findings and Discussion on Posting of Data}

The group functions as a place to disseminate information faster. As observed from Table 7, most of the posts are course related. The most active course is the course CSCP 1014 (Programming 1), followed by CSCI 1013 (Introduction to Computer Applications). The least active group is ENGR 2023 (Dynamics) with only 10 posts and no replies.

Course related postings are mainly on course content, discussion on assignments, lab data, queries on exam, extra information posted by lecturers or students, field trip, etc. Non course related postings may include information on jokes, or other interesting information 
Table 7. Number of Postings and Replies

\begin{tabular}{|l|c|c|c|c|}
\hline Course & $\begin{array}{c}\text { Course Related } \\
\text { Posts }\end{array}$ & $\begin{array}{c}\text { Non-Course Related } \\
\text { Posts }\end{array}$ & Total Posts & Total Replies \\
\hline CHEM 1033 & 15 & 2 & 17 & 14 \\
\hline CHEM 1053 & 15 & 2 & 17 & 7 \\
\hline CSCI 1013 & 30 & 6 & 36 & 34 \\
\hline CSCP 1014 & 59 & 14 & 73 & 232 \\
\hline ENGR 2013 & 17 & 0 & 17 & 6 \\
\hline ENGR 2023 & 10 & 0 & 10 & 0 \\
\hline ENGR 2033 & 22 & 0 & 22 & 7 \\
\hline
\end{tabular}

Table 8. Postings and Replies by Lecturers vs Students

\begin{tabular}{|c|c|c|c|c|}
\hline Course & \multicolumn{2}{|c|}{ Posted By } & \multicolumn{2}{c|}{ Replied By } \\
\hline & Lect. & Stud. & Lect. & Stud. \\
\hline $\begin{array}{c}\text { CHEM } \\
1033\end{array}$ & 10 & 7 & 6 & 8 \\
\hline $\begin{array}{c}\text { CHEM } \\
\text { 1053 }\end{array}$ & 15 & 2 & 2 & 5 \\
\hline CSCI 1013 & 52 & 9 & 11 & 23 \\
\hline CSCP 1014 & 43 & 28 & 52 & 180 \\
\hline $\begin{array}{c}\text { ENGR } \\
\text { 2013 }\end{array}$ & 13 & 4 & 3 & 1 \\
\hline $\begin{array}{c}\text { ENGR } \\
\text { 2023 }\end{array}$ & 10 & 0 & 0 & 0 \\
\hline $\begin{array}{c}\text { ENGR } \\
\text { 2033 }\end{array}$ & 16 & 6 & 1 & 6 \\
\hline
\end{tabular}

Table 8 shows the postings by lecturers and students. As confirmed in the survey 2, most of the posting activities are not by the students but by the lecturers. The students do reply the posts. There are 159 posts by lecturers and 58 by students. When compared to Table 3 , it is observed that only 10 students mentioned that they actively posts in the group. Most of the students reply or "like" posts. This confirms our next conclusion:

Conclusion 7. Lecturers are the main source of information in a Facebook group setup to disseminate information.

Table 9. Correlations between POST and REPLY

\begin{tabular}{|c|c|c|c|}
\hline & $\boldsymbol{N}$ & Correlation & Sig. \\
\hline $\begin{array}{c}\text { POST and } \\
\text { REPLY }\end{array}$ & 51 & 0.632 & 0.000 \\
\hline
\end{tabular}

When looking into correlation between participants who post and reply, it is identified that there is a significant correlation that the participants who post would also replyas shown in Table 9. This confirms the findings in Section 5.3 - Activities on Facebook Group.

\section{Findings and Discussion on Lecturer's Feedback}

All the three lecturers participating in this experiment are using Facebook for the very first time in their respective classes. Previously, the medium of communication with the students are via the students' email and announcement in eLearn. Three aspects would be discussed in this section. Firstly the introductory experience; followed by comparing the communication effect with eLearn; and finally, impact of Facebook 
on students' engagement in class.

\subsection{Introductory Experience}

The introductory experience had been pleasant for all the three lecturers. In fact one of the lecturers is a first time user to Facebook. By separating work and private account, the lecturers do not have the "crossing the boundary" of student-lecturer's relation. As mentioned in Conclusion 5, students have no problem with lecturers being their "friends". Instead it is the lecturers who are more conscious that this boundary be maintained. The introduction of Facebook group to the students was also without problem. The students are familiar with Facebook. Only one from the 103 students, do not have a Facebook account. For the class with the student who does not have a Facebook account, announcements are posted in Facebook group and eLearn.

\subsection{Effectiveness of Communication}

It is observed that the effectiveness of communication with students greatly improved when using Facebook. There was one instance when a field trip for the engineering and chemistry courses has a last minute change. 12 hours before the trip, the company sent a mail requesting students to be dressed in certain attire for safety purposes. This announcement was made on Facebook and 12 hours later; all the students are dressed appropriately for the trip. This would not be possible using eLearn as students tend to login to eLearn once a week, or for some students even do not login with the excuse that they forgot the password.

Another positive experience by one of the lecturer is the reduction of printing costs. Previously, when materials were posted on eLearn or sent by e-mail, students would claim that they cannot login or they did not receive the mail. In order to solve this problem, the lecturer would printout and distribute the notes to the students. Having it posted on Facebook, the lecturer can monitor which students have read the post, and they can no longer give the excuse that they did not receive the document.

The lecturers find that Facebook is a good platform to engage the students. Engagement that previously failed using eLearn, for example discussing the solution to a tutorial, worked on Facebook. One of the main reason is students are mostly connected to Facebook and would be able to respond to the messages faster. As mentioned by one of the lecturer:

"I also use e-learn to post my lecture material and announcements. I realized that the announcements posted in e-learn are checked by my students' typically only when it's necessary, while students are often checking Facebook multiple times per day. Facebook accounts are kept logged in at all times on their smartphone. There would be a beep once they receive notifications. As a result, the moment any announcement or instruction posted, I find that the response is almost immediate."

\subsection{Impact on Students' Engagement}

Students are actually more engaged in the subject than the lecturer expected. Facebook became a platform for students to post their questions and queries. This is where peer to peer learning comes into place, as at times the peers would answer the questions before the lecturer does it. Students also use it as a platform to share and discuss their lab data, experiment methodology and findings. These are initiatives by students themselves. This not only encourages the students but the lecturers as well. Knowing and seeing that students are interested with the course content and intend to do well.

One of the lecturer added alumni into the group, giving the group a chance to interact with seniors who graduated. This also keeps the opportunity for industrial training open. This in a way also keeps students updated on activities in the industry. 


\section{Conclusion and Future Work}

Generally, the feedbacks received, from both lecturers and students are positive. The implementation of Facebook in class does encourage the participation and engagement of students in class. Facebook features that might encourage this participation and engagement are the automatic notifications of new updates, the ease of posting information, and cached login.

This research used Facebook as a tool to disseminate information. The students participated voluntarily. Even though students do initiate posts, most of the posts are initiated by the respective lecturers. This might another motivating factor, as compared to when the participation is graded [15], [17].

Another proposal that seems to work well in maintaining the boundaries between lecturers and students are having a "working account" for the lecturer, and setting up open groups where students can add students to the group.

Compared to the research presented in Section 2 - Related Work, a different level of acceptance from students was discovered. Students covered in this survey have positive attitude about using Facebook as a learning tool. They do not mind having lecturers and course mates as their "Friends". One influencing factor might be the class size. The classes covered in this survey are between 6 and 50 students per class. The class size by Maleko [17] was 230 students. Goh's result shows that students was indecisive and even reluctant to use Facebook as a learning too, did not mention any actual implementation before conducting the survey [14]. It is possible that the students might have a different opinion after experiencing it in class. One aspect that can be looked into is the influence of class size towards the willingness to use Facebook as a learning or engagement tool.

As suggested, the suitable tool for student engagement currently might be Facebook, but it might not be valid in the future. However, it is worth investigating the impact of social engagement tool towards the teaching and learning experience.

\section{References}

[1] Orr, G. (2010). A review of literature in mobile learning: Affordances and constraints. Proceedings of 2010 6th IEEE International Conference on Wireless, Mobile, and Ubiquitous Technologies in Education (pp. 107-111).

[2] Vosloo, S. (2012). Mobile Learning and Policies: Key Issues to Consider (pp. 1-110). Paris, France: United Nations Educational, Scientific and Cultural Organization.

[3] MotiwallaL, F. (2007). Mobile learning: A framework and evaluation. Computers \& Education, 49, 581596.

[4] Hussin, S., Radzi, M. M., Amir, Z., \& Krish, P. (2012). Mobile learning readiness among Malaysian students at higher learning institutes. Asian Social Science, 8.

[5] Ismaill, B. S. F., Azizan, S. N., \& Azman, N. (2013). Teaching via mobile phone: A case study on Malaysian teachers' technology acceptance and readiness. J. Educ. Online, 10, 1-38.

[6] Traxler, J. (2007). Defining, discussing, and evaluating mobile learning: The moving finger writes and having write. Int. Rev. Res. Open Distance Learn, 8, 1-12.

[7] Quinn, C. N. (2011). Mobile Learning: Landscape and Trends. Santa Rosa, CA: The eLearning Guild Research.

[8] Sim, T. Y., Lau, S. L., Zipf, P., \& Kimm, K. (2014). Design and development of a supported tiered software for teaching and learning using a connected mobile learning application. World Appl. Sci. J., 30(30), 247 -255 ,

[9] Blocher, W. (2014). Werkstattbericht "Mobiles Lernen" im Studiengang Wirtschaftsrecht an der Universität Kassel. Baden-Baden, Germany. 
[10] Embi, M. A. (2013). 40 Must-know Web 2.0 Edutools. Bangi.

[11] Embi, M. A. (2013). Web 2.0 interactive tools: A quick guide. Bangi.

[12] Elias, T. (2011). Principles for mobile learning. Int. Rev. Res. Open Distance Learn, 12(2), 144-156.

[13] Junco, R. (2012). The relationship between frequency of Facebook use, participation in Facebook activities, and student engagement. Comput. Educ., 58, 162-171.

[14] Goh, W. W. (Apr. 2013). Students' behavior and perception of using Facebook as a learning tool. Proceedings of 2013 8th Int. Conf. Comput. Sci. Educ. (pp. 731-736).

[15] Judele, R., Tsovaltzi, D., Puhl, T., \& Weinberger, A. (Jan. 2014). Collaborative learning in Facebook: Adverse effects of individual preparation. Proceedings of 2014 47th Hawaii Int. Conf. Syst. Sci. (pp. 1616 -1624).

[16] Jamil, S., Zehra, F., Naqvi, R., \& Bhamani, S. (2013). Impact of Facebook intensity on academic grades of private university students. Proceedings of 5th International Conference on Information and Communication Technologies (pp. 1-10).

[17] Maleko, M., Nandi, D., Hamilton, M., D’Souza, D., \& Harland, J. (Mar. 2013). Facebook versus Blackboard for supporting the learning of programming in a fully online course: The changing face of computing education. Proceedings of 2013 Learn. Teach. Comput. Eng. (pp. 83-89).

[18] Chen, Y. (2011). Learning Styles and Adopting Facebook Technology.

[19] Devadoss, S., \& Foltz, J. (1996). Evaluation of factors influencing student class attendance and performance. Am. J. Agric. Econ., 78(3), 499.

[20] Embi, M. A., \& Nordin, N. M., (2013). Mobile Learning: Malaysian Initiatives \& Research Findings (1st ed.). Bangi: Pusat Pembangunan Akademik, UKM.

[21] Irwin, C., Ball, L., Desbrow, B., \& Leveritt, M. (2012). Students' perceptions of using Facebook as an interactive learning resource at university. Australas. J. Educ. Technol., 28(7), 1221-1232.

[22] Sim, T. Y., \& Vogel-Heuser, B. (2010). Reviews and findings on implementing active learning in a large class environment for Mechatronics and Computer Science students. Proceedings of Educ. Eng. (EDUCON), 2010 IEEE.

[23] AJAX Programming. Tetrieved June 13, 2014, from https://www.facebook.com/help/www/220336891328465.

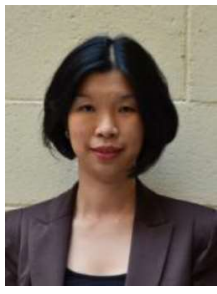

SimTze Ying is currently a senior lecturer in the ADTP program, and teaching computing subjects. She holds a doctorate of engineering degree (Magna Cum Laude) from the University of Kassel, Germany. She acquired her master of science degree from the University Putra Malaysia speacilizing in software engineering.

Dr. Sim Tze Ying pursued her doctorate in Germany and worked as a researcher and teaching assistant in the Department of Embedded System, University of Kassel for 7 years. Her research interest includes variability modelling and engineering education. Before that, she worked in Motorola Semiconductor Malaysia (later known as Freescale Semiconductor) for about five years as a system engineer.

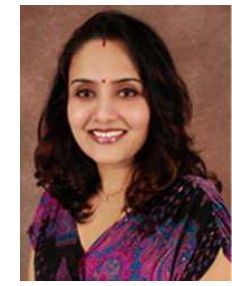

Dewika Naidu is a chemical engineer who graduated with a masters of engineering (environmental) in 2002 and a bachelors (Hons.) of chemical engineering in 1999 from Universiti Teknologi Malaysia which is located in Skudai, Johor, Malaysia.

She has tremendous amount of experience in the industry where she spent numbers of years in the industry attached to several multinational organizations such as Siemens (M) 
Sdn Bhd and German Technical Consultancy-GTZ as an engineer. During her tenure in the industry, she has acquired experiences related to the studies of chemical engineering including business processes and consultancy works. Sharing her industrial experience and passion for teaching, she constantly strives to contribute to the education and industry at large. She is currently an engineering lecturer with the Centre of American education at Sunway University, Malaysia. Her research interest includes innovation in learning and teaching methodologies, air pollution control and environment sustainability.

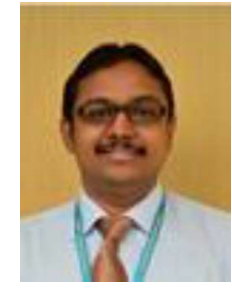

Devandran Apparasamy is currently a lecturer in the ADTP program. He acquired his master of science degree from University Malaysia specializing in analytical chemical and instrumental analysis.

He has been lecturing for more than 7 years for chemistry subjects. He was also involved in a join research with Korean research and manufacturing team on 'Humidity indicator card - Using natural dye' in Malaysian to indicate the percentage of humidity in packaging items for semiconductor products. He has worked with Yokkon Industrial Systems for about three years as a manager. 